\title{
One-factor-at-a-time and response surface statistical designs for improved lactic acid production from beet molasses by Enterococcus hirae ds 10
}

\author{
Mohamed A. Abdel-Rahman ${ }^{1}$ (1) - Saad E. D. Hassan ${ }^{1} \cdot$ Mohamed N. El-Din $^{2} \cdot$ Mohamed S. Azab $^{1} \cdot$ Ehab F. El-Belely ${ }^{1}$. \\ Hassan M. A. Alrefaey ${ }^{1} \cdot$ Tamer Elsakhawy $^{2}$
}

Received: 6 January 2020 / Accepted: 26 February 2020 / Published online: 7 March 2020

(c) Springer Nature Switzerland AG 2020

\begin{abstract}
In this study, the production of lactic acid (LA) from beet molasses, a by-product of the beet sugar industry was investigated using newly isolated potential lactic acid bacteria. Isolate ds 10 was selected amongst 138 bacterial isolates obtained from natural sources. This isolate was identified as Enterococcus hirae ds 10 based on morphological, biochemical and molecular characteristics using 16S rRNA sequence. Direct utilization of molasses achieved low LA production at $2.01 \mathrm{~g} \mathrm{~L}^{-1}$. Different molasses' pretreatment methods were investigated. Molasses treated with EDTA were considered as the best substrate achieving effective LA production at $11.39 \pm 2.07 \mathrm{~g} \mathrm{~L}^{-1}$. Furthermore, medium constituent was optimized, where supplementation of $0.5 \%(\mathrm{w} / \mathrm{v})$ ammonium chloride and $0.05 \%(\mathrm{w} / \mathrm{v})$ yeast extract exhibited the best fermentation medium. Further optimization of fermentation factors was performed by using one-factor-at-a-time (OFAT) and response surface Minitab 18 software approaches. OFAT technique achieved the maximum LA production of $25.4 \pm 0.42 \mathrm{~g} \mathrm{~L}^{-1}$ after $24 \mathrm{~h}$ at sugar molasses conc., $4 \%(\mathrm{w} / \mathrm{v})$; inoculum size, $10 \%(\mathrm{v} / \mathrm{v}) ; \mathrm{pH}, 8.0$; and temperature, $40^{\circ} \mathrm{C}$. Whereas, response surface Minitab 18 software approach resulted in a $60 \%$ increase in LA production achieving $40.69 \mathrm{~g} \mathrm{~L}^{-1}$ at $60 \mathrm{~g} \mathrm{~L}^{-1}$ sugar concentration, $0.625 \mathrm{~g} \mathrm{~L}^{-1}$ yeast extract, $40^{\circ} \mathrm{C}, \mathrm{pH} 8$ and $9.5 \%$ inoculum size. The optimization strategy in this study could achieve a 20 -fold increase in LA production as compared to initial production.
\end{abstract}

Keywords Lactic acid · Beet molasses · Enterococcus hirae ds10 · Response surface optimization · One-factor-at-a-time

\section{Introduction}

Lactic acid (LA) is an organic acid that has vital roles in many industrial applications including food, textile, chemical, cosmetics, and pharmaceutical industries. It has an increasing demand as a feedstock for the manufacturing of biodegradable polylactic acid (PLA) materials as alternatives to petroleum-derived synthetic plastic [1, 2]. Global LA market is forecasted to grow at an estimated CAGR of $19.43 \%$ between 2019-2025 generating around USD 10.06 billion by 2025 (https://www.zionm arketresearch.com/report/lactic-acid-market). LA can be produced by chemical synthesis or biological processes using microbial fermentation. For fermentation processes

Mohamed Ali Abdel-Rahman and Saad El-Din Hassan are contributed equally to this manuscript

Electronic supplementary material The online version of this article (https://doi.org/10.1007/s42452-020-2351-x) contains supplementary material, which is available to authorized users.

$\triangle$ Mohamed A. Abdel-Rahman, mohamedali@kyudai.jp| 'Botany and Microbiology Department, Faculty of Science (Boys), Al-Azhar University, Nasr City, Cairo 11884, Egypt. ${ }^{2}$ Agriculture Microbiology Department, Soil, Water and Environment Research Institute (SWERI), Sakha Agricultural Research Station, Agriculture Research Center (ARC), Giza, Egypt. 
to be competitive, they should meet several characteristics including low-cost substrate/ process, substrate availability, low medium-cost, with little or no by-product formation $[3,4]$.

Substrates are the cornerstone factor affecting LA production costs. Therefore, waste materials are preferred as substrate not only for its cost but also for solving environmental problems related to its disposal. Among several agro-industrial wastes, beet and sugarcane molasses are produced from sugar industries, readily available, cheap raw materials contacting sugars and therefore can be utilized for LA production [5]. Beet molasses constitutes about $5.5 \%(w / w)$ of the beet weight used for sugar production. In Egypt, there is about 15,000 tons of beet molasses as a by-product produced annually from three beet sugar factories [6]. Sucrose is the main sugar in molasses that accounts for around $48-50 \%(w / v)$. These materials also contain limited nitrogen content. On the other hand, it includes some substances such as 5-hydroxymethylfurfural and excessive metallic ions that considered to be microbial inhibitory limiting their efficient utilization [7].

The cost of the fermentation medium is also one of the challenges limiting effective LA production because lactic acid bacteria are fastidious that require a complex nutritional requirement such as peptone, beef extract, and yeast extract. Yeast extract alone has accounted for $38 \%$ of fermentation costs. Some researchers used various low-cost nutrients as nitrogen sources like dry yeast cells, shrimp waste, fish waste hydrolysate or silkworm larvae as an alternative to the high-cost yeast extract [8]. Therefore, the utilization of inexpensive waste materials that contain high nutritional values should add additional saving parameters for LA production $[9,10]$.

Optimization of fermentation factors is critical to maximizing the yield of a specific product before large scale production. Several optimization approaches can be used including classical "one-factor-at-a-time" to recent statistical and mathematical approach, viz. genetic algorithm (GA), artificial neural network (ANN), etc. Each technique has advantages and disadvantages. The combination of various optimization approaches can provide a desirable result [11].

The most common method for improving fermentation medium components and conditions is the "one-factorat-a-time" approach. it is based on fixing all parameters except one independent variable with individual effect on medium components and fermentation conditions. This approach is easy and simple. On the other hand, it is time-consuming, do not investigate the interaction between variable, and expensive especially for conducting a large number of experiments [12]. However, statistical and mathematical approaches are effective and might overcome these limitations. These methods depend on changing more than one factor at a time [13]. They are more effective than "one-factor-at-a-time" approach in screening interactions between different variables and describing the role of the interactions of each component in the process. Of these methods, Response Surface Methodology (RSM) is effective and a suitable design model that explains the combined effect and study several factors affecting fermentation responses by varying them in a limited number of experiments [14].

Therefore, this study aimed to achieve cost-effective LA production from waste materials (beet molasses) using thermotolerant lactic acid bacteria. Establishing cheap fermentation media and optimization of LA production using traditional and statistical methods for enhanced LA production were evaluated.

\section{Material and methods}

\subsection{Media and bacterial isolation}

de Man, Rogosa and Sharpe (MRS) medium is consisted of $\left(\mathrm{g} \mathrm{L}^{-1}\right)$ : glucose, 20; yeast extract, 5; peptone, 10; beef extract, $8 ; \mathrm{K}_{2} \mathrm{HPO}_{4}, 2 ; \mathrm{MgSO}_{4}, 0.1 ; \mathrm{MnSO}_{4}, 0.05$; sodium acetate, 5; ammonium citrate, 2 and tween $80,1 \mathrm{ml}$ [15]. GYP (glucose-yeast extract-peptone) medium is consisted of $\left(\mathrm{g} \mathrm{L}^{-1}\right)$ : glucose, 20; yeast extract, 5; peptone, 5. Solid media were supplemented with $1.5 \%(\mathrm{~W} / \mathrm{V})$ agar, and $1 \%$ $(w / v) \mathrm{CaCO}_{3}$. Modified MRS (mMRS) and modified GYP (mGYP) media were composed of the same components as MRS or GYP, respectively but glucose is substituted by molasses at concentrations mentioned in each experiment. $\mathrm{pH}$ was adjusted at 7.0 using $1 \mathrm{~N} \mathrm{NaOH} / 1 \mathrm{~N} \mathrm{HCl}$. Sterilization was done by autoclaving at $121^{\circ} \mathrm{C}$ for $20 \mathrm{~min}$. Sugar solutions were sterilized separately at $110^{\circ} \mathrm{C}$ for 10 min.

Forty-three natural sources were used for the isolation of LA bacteria. They include milk, rotten fruits, cheese, jam, beet molasses, can molasses, compost, cattle manure, decomposed plant and soil samples that were collected from different localities in Gharbia, Beheira, Cairo and Kafr El-Sheikh Governorates, Egypt. The samples were taken aseptically and packaged into clean bags, then stored at $4{ }^{\circ} \mathrm{C}$.

Bacterial isolation was carried out by two methods. Firstly, either $1 \mathrm{~g}$ or $1 \mathrm{~mL}$ of sample was mixed with $0.75 \%$ $(w / v) \mathrm{NaCl}$ solution and then serially diluted at ten-fold. Each dilution was spread directly onto mMRS and mGYP agar plates and incubated at $40^{\circ} \mathrm{C}$ for $72 \mathrm{~h}$. In the second method, $1 \mathrm{~g}$ of each sample was inoculated into $50 \mathrm{ml}$ of MRS and GYP broth media and then incubated at $40^{\circ} \mathrm{C}$ for $72 \mathrm{~h}$. The broth was then diluted and spread onto the same agar media containing $1 \% \mathrm{CaCO}_{3}$ and incubated at $40{ }^{\circ} \mathrm{C}$ 
for $72 \mathrm{~h}$. Colonies showing a clear zone were individually picked and purified. Purity was checked up using simple and Gram's stains. Gram-positive isolates were assayed for catalase activity.

\subsection{LA production from different substrates}

138 bacterial colonies were tested for the productivity of LA in de Man, Rogosa and Sharpe (MRS) broth medium at $40{ }^{\circ} \mathrm{C}$ for $36 \mathrm{~h}$. After incubation, LA concentration was determined. mMRS containing sucrose, fructose (Sigma Aldrich), or beet molasses as sole carbon source separately were used at $20 \mathrm{~g} \mathrm{~L}^{-1}$ for the most potent isolates. Beet molasse was obtained from the Hamool beet sugar factory (Delta Sugar Company), Kafr El-Sheikh Governorate, Egypt. The sugar content of beet molasses used in this study was about $48-51 \%$ of sucrose, $1 \%$ glucose and fructose, and about $1 \%$ raffinose. Total nitrogen content in the raw molasses is ranged from $0.8-1.2 \%$.

\subsection{Characterization and identification of the most potent isolate}

Morphological characteristics including shape, arrangement and Gram reaction of strain ds 10 were conducted using Gram's stain [16]. Catalase activity using 3\% hydrogen peroxide was assayed as previously described [17]. Biochemical identification using VITEK 2 test was performed in Theodor Bilharz Research Institute, Giza, Egypt. Partial 16S rRNA sequence was analyzed using universal primers 27f, 5'- AGAGTTTGATCCTGGCTCAG-3'; and 1492r, 5- GGTTACCTTGTTACGACTT -3'. Total genomic DNA was extracted from ds 10 cells using Gene Jet genomic DNA purification Kit (Fermentas) and used as a template for PCR. PCR product was sequenced in GATC Biotech Company using $A B I 3730 x I$ DNA sequencer. A similarity index was performed at the GenBank database using the BLAST algorithm.

\subsection{Pretreatment of beet molasses}

For sulphuric acid (SA) treatment, molasses solution (diluted molasses contain $10 \%$ sugar conc.) was adjusted to $\mathrm{pH} 3.0$ using with $1 \mathrm{~N} \mathrm{H}_{2} \mathrm{SO}_{4}$, incubated for $24 \mathrm{~h}$, and then centrifuged for $15 \mathrm{~min}$ at $5000 \times \mathrm{g}$. With $5 \mathrm{~N} \mathrm{NaOH}$, the $\mathrm{pH}$ of the supernatant was readjusted to 7.0 [18]; For activated carbon (AC) treatment, $3 \%(w / v)$ of AC was mixed to the molasses for $1 \mathrm{~h}$, centrifuged at $5000 \times g$ for $15 \mathrm{~min}$. The process was repeated for supernatants and then $\mathrm{pH}$ was adjusted to 7.0 [19]; For tricalcium phosphate (TCP) treatment, molasses was mixed with $2 \%(w / v)$ TCP and autoclaved at $105^{\circ} \mathrm{C}$ for $5 \mathrm{~min}$, cooled, and centrifuged at $5000 \times \mathrm{g}$ for $15 \mathrm{~min}$. The supernatant's $\mathrm{pH}$ was adjusted to 7.0.[19]; for TCP/SA treatment, TCP pretreated supernatants were acidified with concentrated $\mathrm{H}_{2} \mathrm{SO}_{4}$ by mixing for $24 \mathrm{~h}$ at $\mathrm{pH}$ 3.0. The mixture was then centrifuged at $5000 \times g$ for $15 \mathrm{~min}, \mathrm{pH}$ was adjusted to 7.0 [19]; for SA/AC treatment, SA-treated liquors obtained as explained above were subjected to $3 \%(w / v)$ AC as described above [19]; for $\mathrm{TCP} / \mathrm{SA} / \mathrm{AC}$ treatment, molasses solutions pretreated with TCP followed by acidification with SA were subjected to $3 \%(w / v)$ AC treatment as explained above [19]; For potassium ferrocyanide and EDTA treatment, molasses solution was adjusted to $\mathrm{pH} 5.5$ using $5 \mathrm{~N} \mathrm{HCl}$ and heated at $100^{\circ} \mathrm{C}$ for $15 \mathrm{~min} .100 \mathrm{ppm}$ EDTA or potassium ferrocyanide were added to molasses while hot $\left(90^{\circ} \mathrm{C}\right)$, then, mixtures were allowed to settle for $24 \mathrm{~h}$ at room temperature and then centrifuged at $5000 \times g$ for $20 \mathrm{~min}$. The supernatant was then used for fermentation [18]. All experiments were carried in triplicates.

\subsection{Lactic acid production from treated molasses}

For LA production, treated molasses was used at $2 \%(w / v)$ sugar concentration in mMRS media with initial pH 7.0. The inoculum was prepared by transferring $1 \mathrm{~mL}$ of bacteria in glycerol stock culture to test tube containing $9 \mathrm{ml}$ medium for refreshment and incubated for $18 \mathrm{~h}$ at $40{ }^{\circ} \mathrm{C}$ before inoculation in Erlenmeyer flask containing $100 \mathrm{ml}$ of liquid MRS medium for pre-culture. Then, the culture in $500 \mathrm{~mL}$-Erlenmeyer flasks containing $200 \mathrm{~mL}$ of production medium was inoculated with $5 \%$ inoculum (pre-culture with $0.40 \pm 0.03 \mathrm{OD}_{600}$ ) and incubated $40{ }^{\circ} \mathrm{C}$ for $36 \mathrm{~h}$. All experiments were carried in triplicates.

\subsection{Optimization of fermentation medium components:}

\subsubsection{Replacement of medium component with organic/ inorganic nitrogen sources}

This experiment was performed in $500 \mathrm{ml}$-Erlenmeyer flasks with $200 \mathrm{~mL}$ working volume. Molasses solution treated with EDTA was adjusted at $2 \%(w / v)$ initial sugar and used for fermentation with/without other components as follows. Supplementation/exclusion of mMRS media components, or addition of $0.5 \%(\mathrm{w} / \mathrm{v})$ of yeast extract only was firstly investigated. Also, supplementation of $0.5 \%(w / v)$ of ammonium sulfate, ammonium molybdate, ammonium acetate, ammonium chloride, sodium nitrate, urea, peptone, and beef extract was investigated separately on the base of $0.5 \%$ nitrogen source addition equivalent to optimal yeast extract concentration. The media were inoculated with $5 \%(\mathrm{v} / \mathrm{v})$ inoculum and then incubated at $40^{\circ} \mathrm{C}$ for $36 \mathrm{~h}$. 


\subsubsection{Effect mixed nitrogen sources}

Molasses solution containing $20 \mathrm{~g} \mathrm{~L}^{-1}$ initial sugar and $5 \mathrm{~g} \mathrm{~L}^{-1}$ ammonium chloride was supplied with different concentrations of yeast extract $\left(0.5,1,2,3\right.$, and $\left.5 \mathrm{~g} \mathrm{~L}^{-1}\right)$, dried yeast cells $\left(0.5,1,2\right.$, and $\left.3 \mathrm{~g} \mathrm{~L}^{-1}\right)$, or dried fish wastes $\left(0.5,1,2\right.$, and $\left.3 \mathrm{~g} \mathrm{~L}^{-1}\right)$. Fish wastes were collected from local markets in Egypt, dried in the oven at $70^{\circ} \mathrm{C}$ until constant weight. Then grounded to be used for experiments. Also, dried yeast cells or dried fish wastes were used at $5 \mathrm{~g} \mathrm{~L}^{-1}$ without additional ammonium chloride. $\mathrm{pH}$ was adjusted to 7.0 with $1 \mathrm{~N} \mathrm{HCl} / 1 \mathrm{~N} \mathrm{NaOH}$ and sterilized at $121^{\circ} \mathrm{C}$ for $15 \mathrm{~min}$. The experiment was carried out in 500-ml Erlenmeyer flasks containing $200-\mathrm{ml}$ of fermentation medium and incubated for at $40^{\circ} \mathrm{C}$ for $36 \mathrm{~h}$.

\subsection{Design of experiment for optimization of LA production}

\subsubsection{One-factor-at-a-time (OFAT)}

All experiments were carried out in 500-ml Erlenmeyer flasks containing 200-ml of fermentation medium and incubated for $36 \mathrm{~h}$. Treated molasses solution with EDTA was used as substrate supplemented with $0.05 \%(w / v)$ yeast extract and $0.5 \%(w / v)$ ammonium chloride. LA production, $\mathrm{pH}$, optical density and consumed sugar was checked every $12 \mathrm{~h}$.

To study the effect of sugar concentration, treated molasses were used at different concentrations viz., 2, 4, 6,8 and $10 \%(w / v)$ initial sugar. The media were adjusted at $\mathrm{pH} 7.0$ (initial pH value), inoculated with $5 \%$ of the inoculum and incubated at $40^{\circ} \mathrm{C}$ for $36 \mathrm{~h}$. This experiment was conducted at the same condition but with the addition of $\mathrm{CaCO}_{3}$ as a buffering agent at a half concentration of sugar tested. To study the effect of temperature, media with an initial sugar $4 \%(w / v)$ were adjusted to $\mathrm{pH} 7$ and inoculated at $5 \%(v / v)$. Then incubated at different temperature viz., $30,35,40,45$ and $50^{\circ} \mathrm{C}$. To investigate the influence of culture $\mathrm{pH}$, fermentation media with an initial sugar $4 \%$ $(w / v)$ were adjusted to different $\mathrm{pH}$ values (viz., 5.0, 6.0, 7.0, 8.0 and 9.0), inoculated with $5 \%(v / v)$ inoculum size, and incubated at $40^{\circ} \mathrm{C}$ for $36 \mathrm{~h}$. To investigate the optimal inoculum size, cells from stock cultures at wavelength $600 \mathrm{~nm}(0.40 \pm 0.03)$ were transferred to molasses media at different inoculum levels $(1,3,5,7,10$ and $15 \%, v / v)$. The fermentation medium $(\mathrm{pH} 8)$ was then incubated at $40^{\circ} \mathrm{C}$, for $36 \mathrm{~h}$.

\subsubsection{Response surface optimization methods}

Response surface methodology (RSM), and MINITAB 18 statistical package for data analysis. Statistical optimization of media was done using five factors at five levels for the optimization process viz., yeast extract, molasses concentration, temperature, $\mathrm{pH}$ and inoculum size. The experimental data obtained from the design were analyzed by the response surface regression procedure using the following second-order quadratic equation: $Y=B 0+\sum B i X i+\Sigma$ $\mathrm{BiiX}^{2}+\sum$ BijXiXj.

Where, $Y$ was the predicted response which is a dependent variable, i.e. LA production; B0 is an offset term (constant); $B i$ is linear effect; $B i j$ is quadratic effect when $i=j$ and interaction effect when $\mathrm{i}<\mathrm{j}$; Bii is a squared term; $\mathrm{Xi}$ is the variable, which is called as independent variables.

Thirty-two experiments were conducted using a central composite statistical design. The role of each variable, statistical analysis, and their interactions to obtain predicted yield of LA is explained by applying the second-order polynomial method. The results obtained are analyzed statistically and response surface contour plots were constructed. The optimum levels of the variables were determined by running experiments using the optimum values for variables given by response optimization for confirmation of predicted value and the LA production was confirmed.

\subsection{Analytical methods and analyses}

The amount of LA was determined by a colorimetric method according to [20]. Total sugar concentrations were determined by the phenol-sulphuric method [21]. Cells were centrifuged, washed and readjusted with water. The growth was measured spectrophotometry at $600 \mathrm{~nm}$ and described as $\mathrm{OD}_{600}$. The yield of $\mathrm{LA}$-based on the consumed sugar is defined as the ratio of $L A$ produced $\left(\mathrm{g} \mathrm{L}^{-1}\right)$ to the amount of consumed sugar $\left(\mathrm{g} \mathrm{L}^{-1}\right)$. LA productivity ( $\mathrm{g} \mathrm{L}^{-1} \mathrm{~h}^{-1}$ ) was calculated as the ratio of LA concentration to the fermentation time at which the maximum LA concentration was obtained. Maximum LA productivity $\left(\mathrm{g} \mathrm{L}^{-1} \mathrm{~h}^{-1}\right)$ was calculated between each of the sampling periods.

\section{Results}

\subsection{Isolation and screening of LA producing bacteria}

Isolation of microbes from natural sources is the most powerful mean for obtaining genetically-stable strains for industrial products. A basal mMRS and mGYP medium fortified with non-soluble $\mathrm{CaCO}_{3}$ as $\mathrm{pH}$ indicator $(\mathrm{pH}$ 7) were used for the isolation of lactic acid bacteria. Acid production would lower the $\mathrm{pH}$ value and change $\mathrm{CaCO}_{3}$ solubility leading to the formation of a clear zone around the colony. Using 43 natural sources, one hundred and 
thirty-eight acid-producing bacterial isolates were obtained. Of these, forty-three isolates were Gram-positive and catalase-negative and selected for further studies. LA production in mMRS broth medium containing glucose $\left(20 \mathrm{~g} \mathrm{~L}^{-1}\right)$ was investigated as shown in Table S1 (see supplementary data). Amongst all, isolate ds 10 exhibited the highest LA production at $14.0 \mathrm{~g} \mathrm{~L}^{-1}$ after $36 \mathrm{~h}$ with LA yield at $0.9 \mathrm{~g} \mathrm{~g}^{-1}$-consumed glucose. Further screening for the utilization of molasses and molasses-derived sugars (Fig. 1) was investigated. Isolate ds 10, could efficiently utilize all pure sugars (sucrose, glucose, and fructose) with high titer (ranged $14-18 \mathrm{~g} \mathrm{~L}^{-1}$ ) at high yields $(0.66-0.75 \mathrm{~g}$ $\mathrm{g}^{-1}$-consumed sugar) and productivities $(0.272-0.389 \mathrm{~g}$ $\left.\mathrm{L}^{-1} \mathrm{~h}^{-1}\right)$. In contrast, this strain could hardly have utilized crude molasses directly with the production of low titer $\left(2.01 \mathrm{~g} \mathrm{~L}^{-1}\right)$, yield $\left(0.522 \mathrm{~g} \mathrm{~g}^{-1}\right.$-consumed sugar $)$ and productivity $\left(0.055 \mathrm{~g} \mathrm{~L}^{-1} \mathrm{~h}^{-1}\right)$. As a result, isolate $\mathrm{ds} 10$ was selected as the most potent isolate for further studies aiming to improve LA production from beet molasses. This strain was isolated from soil samples collected from the Kafr-Elsheikh governorate, Egypt.

\subsection{Characterization and identification of isolate ds10}

Morphological and physiological properties of isolate ds10 were investigated. This isolate is Gram-positive, $\mathrm{KOH}$ negative, cocci, catalase-negative, and none spore former. This isolate was also identified using VITEK 2 that assesses various metabolic activities such as alkalization, acidification, enzyme hydrolysis, and growth in the presence of inhibitory compounds. As shown in Table S2 (see supplementary data), isolate ds 10 showed $93 \%$ similarly to Enterococcus faecium.

Molecular identification based on 16S rRNA sequence analysis showed $99 \%$ identity to that of reference strain Enterococcus hirae strain LMG 6399 (accession number NR-114783.2) available in the NCBI. The phylogenetic analysis of isolate is shown in Fig. 2. Accordingly, we concluded that isolate ds 10 was identified as Enterococcus hirae ds 10. The 16S rRNA sequence of this isolate was deposited in GenBank under the accession number MK910108.

\subsection{Pretreatment of molasses for effective LA production}

The production of LA by strain ds 10 from pretreated beet molasses using different chemicals is shown in Fig. 3. Beet molasses treated with $\mathrm{H}_{2} \mathrm{SO}_{4}, \mathrm{Ca}_{3}\left(\mathrm{PO}_{4}\right)_{2}$, activated carbon and $\mathrm{K}_{4} \mathrm{Fe}(\mathrm{CN})_{6}$ separately or in mixture showed decreased fermentation efficiency in terms of produced LA. On the other hand, treatment with EDTA exhibited better results regarding LA concentration, yield, and productivity compared with untreated molasses and other treatments. At which, the highest value of $L A$ at $11.3 \pm 2.07 \mathrm{~g} \mathrm{~L}^{-1}$ with LA yield of $0.74\left(\mathrm{~g} \mathrm{~g}^{-1}\right.$-consumed sugar) and productivity of $0.32 \mathrm{~g} \mathrm{~L}^{-1} \mathrm{~h}^{-1}$ was obtained.

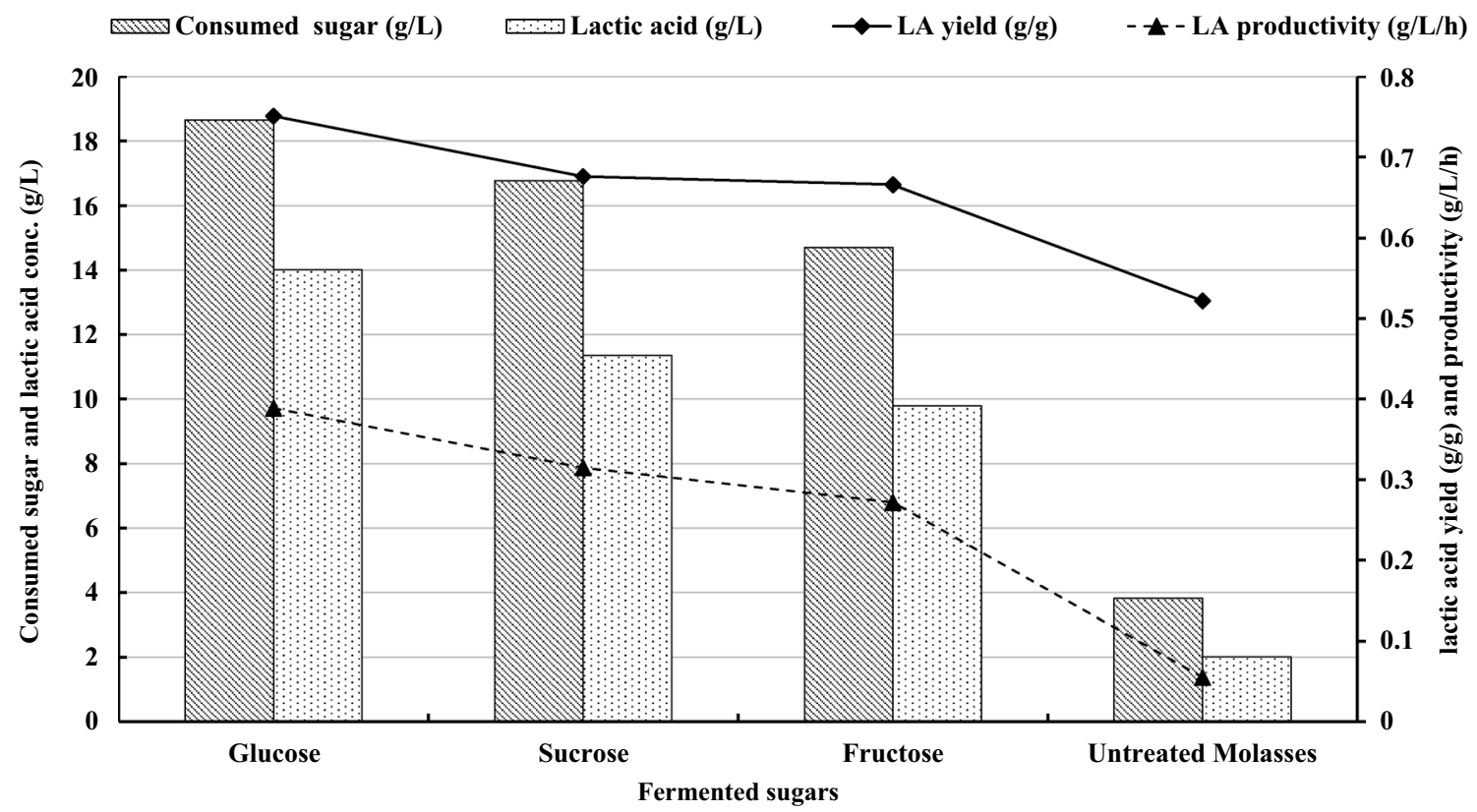

Fig. 1 Utilization of molasses and molasses-derived sugars by bacterial isolate $\mathrm{ds} 10$ 
Fig. 2 Phylogenetic tree based on 16S rRNA gene sequences. The evolutionary history was inferred by using the maximum likelihood method based on the Kimura two-parameter model. The percentage of replicate trees in which the associated taxa clustered together in the bootstrap test (1000 replicates) is shown next to the branches. Black triangle indicate the bacterial isolate ds 10 in this study. GenBank accession numbers of reference sequences are indicated. Bar 0.02 nucleotide substitutions per position

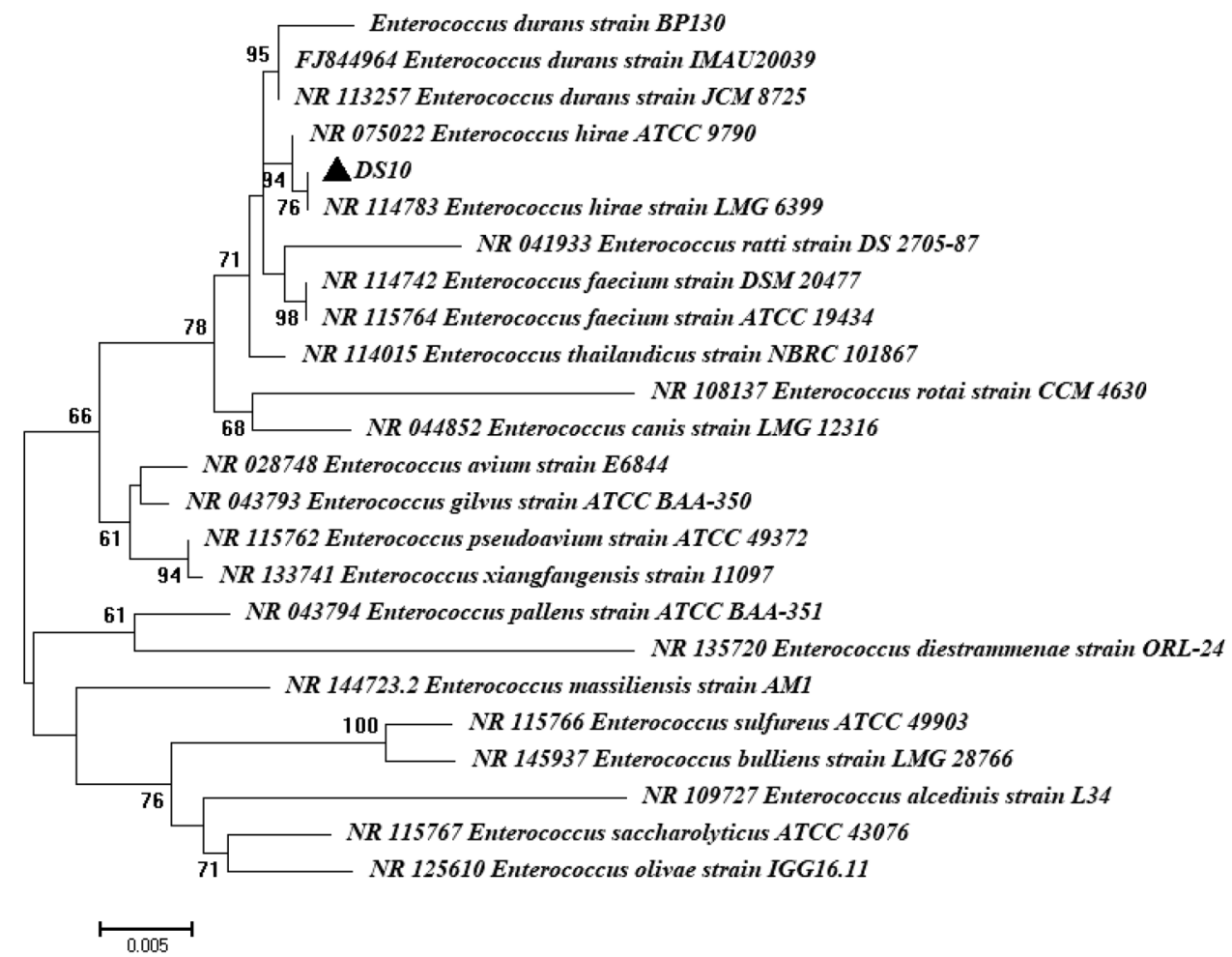

95 FJ844964 Enterococcus durans strain IMAU20039

NR 113257 Enterococcus durans strain JCM 8725

$\triangle D S 10$

76 NR 114783 Enterococcus hirae strain LMG 6399

NR 114742 Enterococcus faecium strain DSM 20477

NR 115764 Enterococcus faecium strain ATCC 19434

Enterococcus canis strain $L M G 1$

NR 115762 Enterococcus pseudoavium strain ATCC 49372

94 LR 133741 Enterococcus xiangfangensis strain 11097 ,

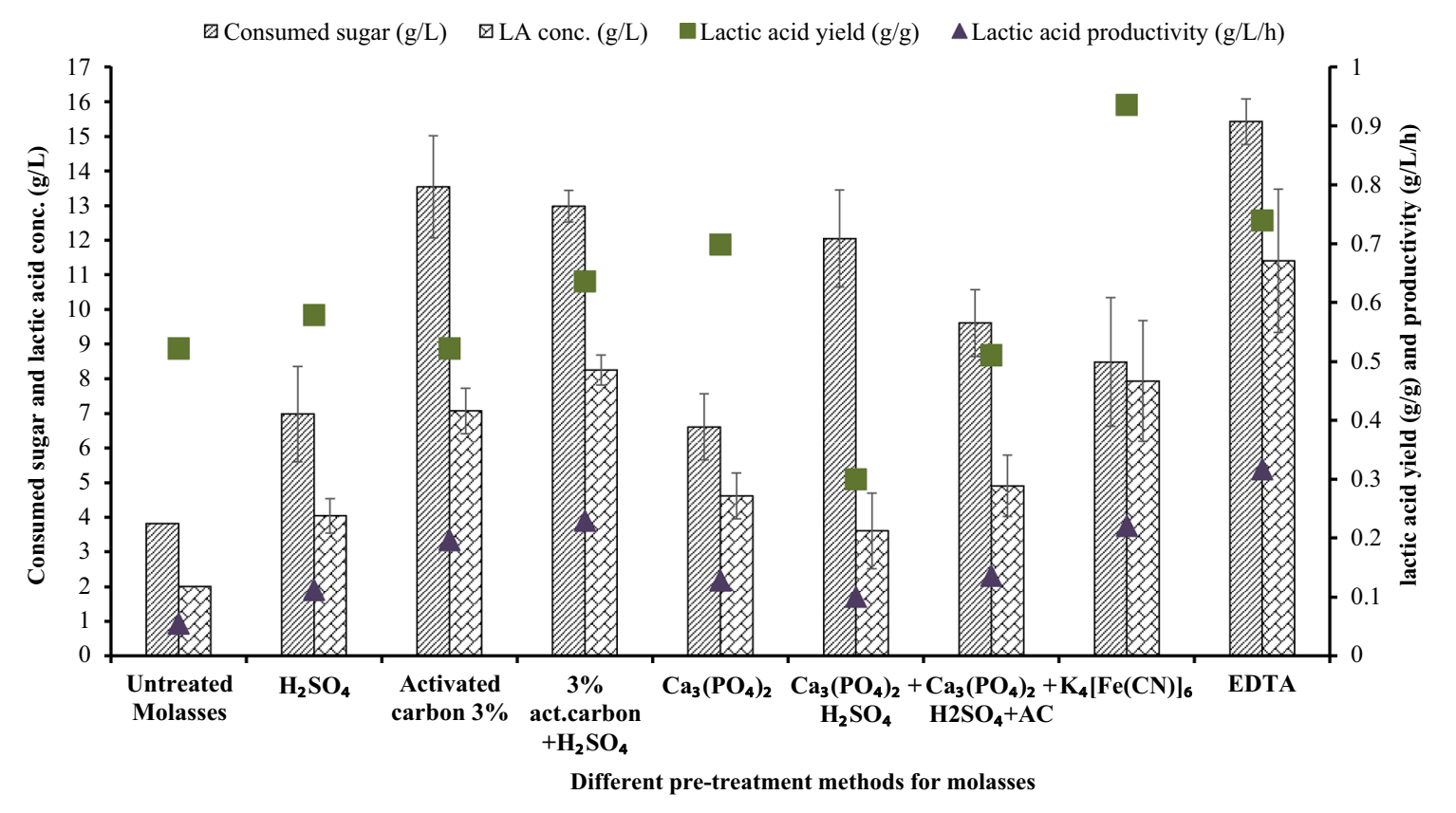

Fig. 3 Effect of treatment of beet molasses on lactic acid fermentation by Enterococcus hirae ds 10

\subsection{Optimization of production medium}

\subsubsection{Replacement of medium component with different nitrogen sources}

SN Applied Sciences
LA fermentations using EDTA-treated molasses (2\%, initial sugar $w / v)$ supplemented with $0.5 \%(w / v)$ nitrogen source were compared with that obtained without the addition of yeast extract and that supplemented with MRS medium components. Fermentations were conducted at 
$40{ }^{\circ} \mathrm{C}, \mathrm{pH} 7$, for $36 \mathrm{~h}$ with $5 \%(\mathrm{v} / \mathrm{v})$ inoculum. As shown in Table 1, the supplementation of MRS medium components resulted in LA production at $11.3 \mathrm{~g} \mathrm{~L}^{-1}$. On the other hand, supplementation of yeast extract only exhibited LA concentrations at $7.35 \pm 0.08 \mathrm{~g} \mathrm{~L}^{-1}$ with yield $0.63 \mathrm{~g} \mathrm{~g}^{-1}$ consumed sugar. Ammonium chloride was the next best nitrogen source where it showed LA concentration at $4.04 \pm 0.02 \mathrm{~g} \mathrm{~L}^{-1}$ with yield $0.96 \mathrm{~g} \mathrm{~g}^{-1}$-consumed sugar. Although dried yeast cells achieved LA production of $4.18 \mathrm{~g} \mathrm{~L}^{-1}$, it achieved a lower yield at $0.81 \mathrm{~g} / \mathrm{g}$. Other nitrogen sources exhibited lower LA production ranged 1.29-3.6 $\mathrm{g} \mathrm{L}^{-1}$. Exclusion of medium components results in only $0.86 \mathrm{~g} \mathrm{~L}^{-1} \mathrm{LA}$ with very low LA yield at $0.340 \mathrm{~g} \mathrm{~g}^{-1}$-consumed sugar.

\subsubsection{Effect of mixed nitrogen source}

Due to the high cost of yeast extract, this experiment was conducted to reduce the cost of fermentation medium components. Ammonium chloride was used as the main nitrogen source while yeast extract, dried yeast cells, or dried fish wastes were used at different concentrations as supplementary vitamin sources for LAB growth and LA fermentation (Table 2). During fermentation, it was observed that the highest LA was produced with the lowest concentration of yeast extract $0.5 \mathrm{~g} \mathrm{~L}^{-1}$ achieving $14.1 \pm 0.24 \mathrm{~g} \mathrm{~L}^{-1}$ at LA yield of $0.84 \mathrm{~g} \mathrm{~g}^{-1}$-consumed sugar and productivity of $0.39 \mathrm{~g} \mathrm{~L}^{-1} \cdot \mathrm{h}^{-1}$ and decreased gradually when yeast extract was increased.
On the other hand, treated molasses supplemented with dried yeast $\left(2 \mathrm{~g} \mathrm{~L}^{-1}\right)$ gave the highest LA concentration of $7.68 \pm 0.35 \mathrm{~g} \mathrm{~L}^{-1}$ compared with the other concentrations. But almost half the amount of LA was produced compared with yeast extract. Besides, supplementation of dried fish wastes as vitamin source was unsuccessful, resulting in very low concentrations of LA ranged $0.29-0.86 \mathrm{~g} \mathrm{~L}^{-1}$. Also, it was difficult to measure bacterial growth. Therefore, yeast extract $0.5 \mathrm{~g} \mathrm{~L}^{-1}$ of yeast extract with $5 \mathrm{~g} \mathrm{~L}^{-1}$ ammonium chloride was selected as the best component for LA production by strain $\mathrm{ds} 10$.

\subsection{Different designs for optimization of LA production}

\subsubsection{One-factor-at-a-time (OFAT) method}

To investigate the optimal conditions for utilization of molasses by Enterococcus hirae ds 10, different initial sugar concentrations $(2 \%, 4 \%, 6 \%, 8 \%$ and $10 \%, w / v)$ were investigated for LA production. As shown in Table 3, LA concentration was increased with the decrease of sugar concentration and LA production was observed to be in a limited range of $17-21 \mathrm{~g} \mathrm{~L}^{-1}$. The highest $L A$ concentration $\left(20.92 \pm 0.53 \mathrm{~g} \mathrm{~L}^{-1}\right)$ was obtained at the sugar concentration of $20 \mathrm{~g} \mathrm{~L}^{-1}$ with an LA yield of approximately $1.0 \mathrm{~g} \mathrm{~g}^{-1}$-consumed sugar. The result implies that Enterococcus hirae ds 10 could metabolize molasses sugars homofermentatively through the EMP pathway. To remove such LA limitations, $\mathrm{CaCO}_{3}$ was added to the medium. But almost

Table 1 Effect of medium components on LA production from EDTA-treated molasses by Enterococcus hirae ds 10

\begin{tabular}{lclcccc}
\hline Medium components & $\mathrm{OD}_{600 \mathrm{~nm}}{ }^{\mathrm{a}}$ & Final $\mathrm{pH}$ & $\begin{array}{l}\text { Consumed } \\
\text { sugars }\left(\mathrm{g} \mathrm{L}^{-1}\right)\end{array}$ & LA conc. $\left(\mathrm{g} \mathrm{L}^{-1}\right)^{\mathrm{b}}$ & $Y_{\mathrm{LA}}\left(\mathrm{g} \cdot \mathrm{g}^{-1}\right)^{\mathrm{c}}$ & $P_{\mathrm{LA}}\left(\mathrm{g} \mathrm{L}^{-1} \cdot \mathrm{h}^{-1}\right)^{\mathrm{d}}$ \\
\hline MRS & $0.53 \pm 0.04$ & $5.36 \pm 0.40$ & $15.4 \pm 1.65$ & $11.39 \pm 2.07$ & 0.74 & 0.32 \\
Molasses only & $0.20 \pm 0.03$ & $5.03 \pm 0.05$ & $2.48 \pm 0.37$ & $0.86 \pm 0.35$ & 0.34 & 0.02 \\
Yeast extract $\left(5 \mathrm{~g} \mathrm{~L}^{-1}\right)$ & $1.05 \pm 0.04$ & $4.56 \pm 0.05$ & $11.6 \pm 0.53$ & $7.35 \pm 0.08$ & 0.63 & 0.20 \\
Amm. molybdate $\left(5 \mathrm{~g} \mathrm{~L}^{-1}\right)$ & $0.34 \pm 0.32$ & $5.80 \pm 0.0$ & $5.29 \pm 0.86$ & $2.02 \pm 0.02$ & 0.38 & 0.05 \\
Amm. Chloride $\left(5 \mathrm{~g} \mathrm{~L}^{-1}\right)$ & $0.20 \pm 0.02$ & $5.10 \pm 0.0$ & $4.17 \pm 0.21$ & $4.04 \pm 0.02$ & 0.96 & 0.11 \\
Amm. acetate $\left(5 \mathrm{~g} \mathrm{~L}^{-1}\right)$ & $0.12 \pm 0.02$ & $5.60 \pm 0.1$ & $3.04 \pm 0.29$ & $1.29 \pm 0.22$ & 0.42 & 0.03 \\
Urea $\left(5 \mathrm{~g} \mathrm{~L}^{-1}\right)$ & $0.09 \pm 0.01$ & $5.35 \pm 0.07$ & $3.42 \pm 0.85$ & $2.45 \pm 0.33$ & 0.71 & 0.06 \\
NaNO $\left(5 \mathrm{~g} \mathrm{~L}^{-1}\right)$ & $0.23 \pm 0.15$ & $5.00 \pm 0.1$ & $3.42 \pm 0.53$ & $1.58 \pm 0.88$ & 0.46 & 0.04 \\
Peptone $\left(5 \mathrm{~g} \mathrm{~L}^{-1}\right)$ & $0.35 \pm 0.00$ & $4.80 \pm 0.0$ & $3.83 \pm 0.70$ & $3.60 \pm 0.40$ & 0.94 & 0.10 \\
Beef extract $\left(5 \mathrm{~g} \mathrm{~L}^{-1}\right)$ & $0.21 \pm 0.02$ & $4.90 \pm 0.0$ & $3.42 \pm 0.85$ & $2.02 \pm 0.13$ & 0.59 & 0.05 \\
Dried yeast cells $\left(5 \mathrm{~g} \mathrm{~L}^{-1}\right)$ & $0.94 \pm 0.03$ & $4.80 \pm 0.0$ & $5.11 \pm 0.47$ & $4.18 \pm 0.53$ & 0.81 & 0.11 \\
Dried fish wastes $\left(5 \mathrm{~g} \mathrm{~L}^{-1}\right)$ & $\mathrm{NA}$ & $5.30 \pm 0.1$ & $11.1 \pm 0.06$ & $1.29 \pm 0.35$ & 0.11 & 0.03 \\
\hline
\end{tabular}

NA, not analyzed

${ }^{a} O D$, optical density

${ }^{\mathrm{b}}$ Lactic acid concentration after $36 \mathrm{~h}$

'Lactic acid yield

d Lactic acid productivity at the end of fermentation time 
Table 2 The effect of mixing ammonium chloride $\left(5 \mathrm{~g} \mathrm{~L}^{-1}\right)$ with different concentration of yeast extract on LA production from molasses by Enterococcus hirae ds 10

\begin{tabular}{|c|c|c|c|c|c|c|c|}
\hline \multicolumn{2}{|c|}{$\begin{array}{l}\text { Amm. chloride }\left(5 \mathrm{~g} \mathrm{~L}^{-1}\right) \text { supple- } \\
\text { mented with: }\end{array}$} & \multirow[t]{2}{*}{$\mathrm{OD}_{600 \mathrm{~nm}}^{\mathrm{a}}$} & \multirow[t]{2}{*}{ Final pH } & \multirow[t]{2}{*}{$\begin{array}{l}\text { Consumed } \\
\text { sugars }\left(g \mathrm{~L}^{-1}\right)\end{array}$} & \multirow[t]{2}{*}{ LA conc. $\left(g^{-1}\right)^{b}$} & \multirow[t]{2}{*}{$Y_{\mathrm{LA}}\left(\mathrm{g} \mathrm{g}^{-1}\right)^{\mathrm{C}}$} & \multirow[t]{2}{*}{$P_{\mathrm{LA}}\left(\mathrm{g} \mathrm{L}^{-1} \mathrm{~h}^{-1}\right)^{\mathrm{d}}$} \\
\hline Supplementation & Conc. $\left(\mathrm{g} \mathrm{L}^{-1}\right)$ & & & & & & \\
\hline \multirow[t]{4}{*}{ Yeast extract } & 0.5 & $0.71 \pm 0.09$ & $4.46 \pm 0.05$ & $16.7 \pm 1.06$ & $14.0 \pm 0.24$ & 0.84 & 0.39 \\
\hline & 1.0 & $0.86 \pm 0.04$ & $4.50 \pm 0.0$ & $8.5 \pm 1.77$ & $8.37 \pm 0.40$ & 0.98 & 0.23 \\
\hline & 2.0 & $0.9 \pm 0.04$ & $4.50 \pm 0$ & $11.9 \pm 1.83$ & $7.22 \pm 0.24$ & 0.61 & 0.20 \\
\hline & 3.0 & $0.95 \pm 0.03$ & $4.50 \pm 0$ & $9.73 \pm 2.95$ & $5.77 \pm 0.20$ & 0.59 & 0.16 \\
\hline \multirow[t]{5}{*}{ Dried yeast cells } & 0.5 & $0.95 \pm 0.03$ & $4.90 \pm 0$ & $9.67 \pm 2.29$ & $5.77 \pm 0.53$ & 0.59 & 0.16 \\
\hline & 1.0 & $0.95 \pm 0.03$ & $4.80 \pm 0$ & $10.2 \pm 0.53$ & $6.68 \pm 1.42$ & 0.64 & 0.18 \\
\hline & 2.0 & $0.94 \pm 0.03$ & $4.80 \pm 0$ & $11.1 \pm 2.26$ & $7.68 \pm 0.35$ & 0.69 & 0.21 \\
\hline & 3.0 & $0.94 \pm 0.03$ & $4.80 \pm 0$ & $6.11 \pm 1.47$ & $4.18 \pm 0.53$ & 0.68 & 0.12 \\
\hline & 5.0 & $0.94 \pm 0.03$ & $4.80 \pm 0$ & $3.86 \pm 1.91$ & $2.59 \pm 1.54$ & 0.67 & 0.07 \\
\hline \multirow[t]{5}{*}{ Dried fish wastes } & 0.5 & NA & $5.10 \pm 0.1$ & $7.16 \pm 0.95$ & $0.72 \pm 0.40$ & 0.1 & 0.02 \\
\hline & 1.0 & NA & $5.00 \pm 0.17$ & $8.92 \pm 1.85$ & $0.86 \pm 0.35$ & 0.09 & 0.02 \\
\hline & 2.0 & NA & $5.15 \pm 0.21$ & $9.67 \pm 0.45$ & $0.58 \pm 0.81$ & 0.06 & 0.02 \\
\hline & 3.0 & NA & $5.15 \pm 0.21$ & $9.67 \pm 0.45$ & $0.58 \pm 0.81$ & 0.06 & 0.02 \\
\hline & 5.0 & NA & $5.30 \pm 0.1$ & $12.1 \pm 1.06$ & $0.29 \pm 0.35$ & 0.02 & 0.01 \\
\hline
\end{tabular}

NA, not analyzed AC

${ }^{\mathrm{a} O D}$, optical density

${ }^{b}$ Lactic acid concentration after $36 \mathrm{~h}$

'Lactic acid yield

${ }^{d}$ Lactic acid productivity at the end of fermentation time

all fermentation parameters were decreased with the addition of $\mathrm{CaCO}_{3}$ (Data not shown). As all sugars were almost consumed when $2 \%$ sugar concentration was used, further improvement OFAT experiments were conducted at $4 \%$ $(w / v)$.

The effect of different incubation temperatures was studied at the initial sugar concentration of $4 \%(w / v)$ and $\mathrm{pH}$ 7. The data indicated that the optimal temperature for LA fermentation by strain ds 10 was $40^{\circ} \mathrm{C}$, where LA was $14.5 \pm 0.20 \mathrm{~g} \mathrm{~L}^{-1}(24 \mathrm{~h})$ at a yield of $92.0 \mathrm{~g} \mathrm{~g}^{-1}$-consumed sugar. Above and below this value, all fermentation parameters were decreased achieving LA concentration ranged 4.04-11.5 g L $\mathrm{g}^{-1}$ (Table 3).

For optimizing the $\mathrm{pH}$, fermentation media was adjusted to different $\mathrm{pH}(5.0,6.0,7.0,8.0$ and 9.0$)$ at $40^{\circ} \mathrm{C}$. The maximum LA production $\left(21.0 \pm 0.2 \mathrm{~g} \mathrm{~L}^{-1}\right)$ with a yield of $0.93 \mathrm{~g} \mathrm{~g}^{-1}$-consumed sugar was achieved at $\mathrm{pH} 8.0$ after $36 \mathrm{~h}$. However, at higher and lower $\mathrm{pH}$ levels, decrease in all parameters were obtained (Table 3 ).

To find the effect of inoculum size on LA production, fermentation medium ( $\mathrm{pH} 8$ ) was inoculated with different inoculum sizes $(1,3,5,10$ and $15 \%, v / v)$, separately and incubated at $40^{\circ} \mathrm{C}$ for $36 \mathrm{~h}$. An increase in sugar molasses utilization and LA production and resulted in a decrease in fermentation time was observed when bacterial inoculum size increased (Table 3). The maximum LA production of
$25.4 \pm 0.42 \mathrm{~g} \mathrm{~L}^{-1}(24 \mathrm{~h})$ was obtained with $10 \%(\mathrm{v} / \mathrm{v})$ inoculum size.

\subsubsection{Statistical optimization design}

To maximize LA production, Response Surface Analysis of the Minitab 18 software (version 18) was used. 5 variables of yeast extract, sugar molasses concentration, temperature, $\mathrm{pH}$ and inoculum size that was found to be significant by classical OFAT design were investigated. Run design leads to a set of 32 experimental runs as shown in Table 4 . Each independent variable was tested at two levels, high and low, which are denoted by $(+1)$ and $(-1)$, respectively. Based on the data, yeast extract concentrations were $(+)$ 0.25 and $(-) 1 \mathrm{~g} \mathrm{~L}^{-1}$, molasses concentrations were $(+) 40$ and $(-) 80 \mathrm{~g} \mathrm{~L}^{-1}$, temperature was $(+) 35$ and $(-) 45^{\circ} \mathrm{C}$, $\mathrm{pH}$ were $(+) 7$ and $(-) 9$, and the inoculum size were $(+) 7$ and $(-) 12 \%$. LA production was taken as the response for each variable. The interactions between variables and statistical analysis indicated the possibility of enhancement in LA production. The model showed that the highest LA production achieved in the verification experiment was $40.6 \mathrm{~g} \mathrm{~L}^{-1}$ (as seen in run 30).

Results indicated that the maximum LA production achieved by Enterococcus hirae ds 10 was recorded with high levels (positive effect) of yeast extract, sugar molasses 
Table 3 Variables used in OFAT technique for optimization of lactic acid production from Enterococcus hirae ds10 using molasses as substrate

\begin{tabular}{|c|c|c|c|c|c|c|c|c|}
\hline Variable & Conc./Value & $\mathrm{OD}_{600 \mathrm{~nm}}{ }^{\mathrm{a}}$ & Final $\mathrm{pH}$ & $\begin{array}{l}\text { Consumed } \\
\text { sugars ( } g \\
\mathrm{~L}^{-1} \text { ) }\end{array}$ & $\begin{array}{l}\text { LA conc. }\left(\mathrm{g} \mathrm{L}^{-1}\right) \\
\text { at indicated time }\end{array}$ & $Y_{\mathrm{LA}}\left(\mathrm{g} \mathrm{g}^{-1}\right)^{\mathrm{b}}$ & $P_{\mathrm{LA}}\left(\mathrm{g} \mathrm{L}^{-1} \cdot \mathrm{h}^{-1}\right)^{\mathrm{c}}$ & $\begin{array}{l}\text { Max. } P_{L A} \\
\left(g^{-1} \cdot h^{-1}\right) \\
(0-12 h)\end{array}$ \\
\hline \multirow{5}{*}{$\begin{array}{l}\text { Sugar concentration } \\
(\%, w / v)\end{array}$} & 2 & $0.78 \pm 0.01$ & $4.7 \pm 0.0$ & $20.9 \pm 0.27$ & $20.9 \pm 0.53(12 h)$ & 0.99 & 1.74 & 1.69 \\
\hline & 4 & $0.90 \pm 0.01$ & $4.83 \pm 0.09$ & $16.8 \pm 0.95$ & $14.5 \pm 0.20(24 h)$ & 0.86 & 0.61 & 0.96 \\
\hline & 6 & $0.91 \pm 0.01$ & $5.00 \pm 0.08$ & $21.4 \pm 0.70$ & $18.6 \pm 1.54(36 \mathrm{~h})$ & 0.86 & 0.52 & 1.40 \\
\hline & 8 & $0.96 \pm 0.00$ & $5.10 \pm 0.08$ & $26.8 \pm 0.06$ & $18.6 \pm 0.35(36 h)$ & 0.69 & 0.52 & 0.94 \\
\hline & 10 & $1.14 \pm 0.00$ & $5.16 \pm 0.04$ & $26.8 \pm 0.30$ & $17.1 \pm 0.20(36 h)$ & 0.64 & 0.48 & 0.80 \\
\hline \multirow[t]{5}{*}{ Temperature $\left({ }^{\circ} \mathrm{C}\right)$} & 30 & $0.33 \pm 0.01$ & $5.73 \pm 0.12$ & $4.97 \pm 0.46$ & $4.04 \pm 0.20(36 h)$ & 0.81 & 0.11 & 0.28 \\
\hline & 35 & $0.67 \pm 0.01$ & $4.80 \pm 0.08$ & $9.48 \pm 0.79$ & $7.07 \pm 0.41(36 \mathrm{~h})$ & 0.75 & 0.19 & 0.41 \\
\hline & 40 & $0.87 \pm 0.02$ & $4.86 \pm 0.04$ & $15.8 \pm 0.95$ & $14.5 \pm 0.20(24 h)$ & 0.92 & 0.61 & 0.98 \\
\hline & 45 & $0.50 \pm 90.01$ & $4.80 \pm 0.08$ & $14.7 \pm 2.53$ & $11.5 \pm 1.81(36 \mathrm{~h})$ & 0.78 & 0.32 & 0.60 \\
\hline & 50 & $0.39 \pm 0.01$ & $5.10 \pm 0.00$ & $5.16 \pm 1.41$ & $4.33 \pm 0.35(24 \mathrm{~h})$ & 0.84 & 0.18 & 0.28 \\
\hline \multirow[t]{5}{*}{$\mathrm{pH}$} & 5 & $0.23 \pm 0.01$ & $5.00 \pm 0.0$ & $10.4 \pm 0.26$ & $6.78 \pm 0.20(36 \mathrm{~h})$ & 0.65 & 0.18 & 0.47 \\
\hline & 6 & $0.38 \pm 0.00$ & $4.93 \pm 0.05$ & $12.6 \pm 0.26$ & $8.37 \pm 0.88(24 h)$ & 0.66 & 0.34 & 0.64 \\
\hline & 7 & $0.29 \pm 0.00$ & $5.06 \pm 0.04$ & $12.8 \pm 0.46$ & $11.2 \pm 0.35(36 \mathrm{~h})$ & 0.87 & 0.31 & 0.78 \\
\hline & 8 & $0.42 \pm 0.01$ & $5.00 \pm 0.0$ & $22.6 \pm 0.53$ & $21.0 \pm 0.20(24 \mathrm{~h})$ & 0.93 & 0.87 & 1.44 \\
\hline & 9 & $0.23 \pm 0.01$ & $5.36 \pm 0.04$ & $14.5 \pm 0.46$ & $13.7 \pm 0.53(24 h)$ & 0.94 & 0.57 & 1.08 \\
\hline \multirow[t]{6}{*}{ Inoculum size $(\%, v / v)$} & 1 & $0.52 \pm 0.03$ & $4.83 \pm 0.04$ & $13.6 \pm 0.95$ & $10.2 \pm 0.53(24 \mathrm{~h})$ & 0.75 & 0.42 & 0.67 \\
\hline & 3 & $0.75 \pm 0.04$ & $4.70 \pm 0.1$ & $15.4 \pm 0.26$ & $10.9 \pm 0.41(36 h)$ & 0.71 & 0.30 & 0.78 \\
\hline & 5 & $0.42 \pm 0.01$ & $4.73 \pm 0.04$ & $22.6 \pm 0.53$ & $21.0 \pm 0.20(24 h)$ & 0.93 & 0.87 & 1.44 \\
\hline & 7 & $0.69 \pm 0.02$ & $4.70 \pm 0.01$ & $25.6 \pm 0.70$ & $22.6 \pm 0.20(36 \mathrm{~h})$ & 0.88 & 0.62 & 1.47 \\
\hline & 10 & $0.67 \pm 0.00$ & $4.66 \pm 0.07$ & $30.1 \pm 0.95$ & $25.4 \pm 0.42(24 h)$ & 0.84 & 1.05 & 2.07 \\
\hline & 15 & $0.54 \pm 0.01$ & $4.66 \pm .03$ & $22.0 \pm 0.26$ & $18.3 \pm 0.73(24 h)$ & 0.83 & 0.76 & 1.48 \\
\hline
\end{tabular}

${ }^{\mathrm{a} O D}$, optical density

${ }^{\mathrm{b}}$ Lactic acid yield

'Lactic acid productivity at the end of fermentation time

concentration, temperature, $\mathrm{pH}$ and inoculum size. Whereas, the LA produced by studied strain ranged from 19.4 to $40.6 \mathrm{~g} \mathrm{~L}^{-1}$ compared by maximum LA produced $25.4 \pm 0.42 \mathrm{~g} \mathrm{~L}^{-1}(24 \mathrm{~h})$ was observed by classical OFAT.

\section{Discussion}

Commercial LA production requires the use of robust biocatalysts utilizing a low-cost substrate with a minimal amount of nitrogenous source to meet global needs [22]. Besides, tolerance to high temperature, production of negligible amounts of byproducts is highly recommended to avoid contamination risk and decrease the down streaming processes cost [23]. In this study, isolation and identification of the thermotolerant bacterium for the production of high amounts of LA using cheap agro-industrial wastes and low-cost nitrogen sources were investigated.

A basal mMRS and MGYP media supplemented with $\mathrm{CaCO}_{3}$ were used for the isolation of $L A B$ from various natural sources. Acid production would change $\mathrm{pH}$ and solubility $\mathrm{CaCO}_{3}$ forming a clearing zone around microbial growth. One hundred thirty-eight bacterial isolates were obtained, of these, 43 isolates are considered as LAB based on preliminary characteristics of LA production, Gram-positive, spore formation, and catalase-negativity. Based on screening data for utilization of molasses, sucrose, glucose, and fructose, isolate ds 10 was selected as the most potent strain for this study. The selected isolate was characterized by a bacterial identification kit of VITEK 2 system using $B C L$ colorimetric card and $16 \mathrm{~S}$ rRNA sequencing. The phylogenetic analysis of strain ds 10 using its 165 rRNA sequence data provide additional evidence that is related to genus Enterococcus. Strain ds 10 had the highest homology (99\% identity) to that of reference strain Enterococcus hirae strain LMG 6399 16S ribosomal RNA. Accordingly, we concluded that the strain ds 10 was identified as Enterococcus hirae ds 10 .

Many reported studies for LA production had used pure substrates such as lactose or glucose that is costly and competitive with food and feed. In this study, we aimed to reduce the cost by using waste products such as beet molasses as inexpensive industrial by-products containing fermentable sugars $[2,10,24]$. It contains approximately 
Table 4 Results for optimization of five variables for production of lactic acid by Enterococcus hirae ds 10

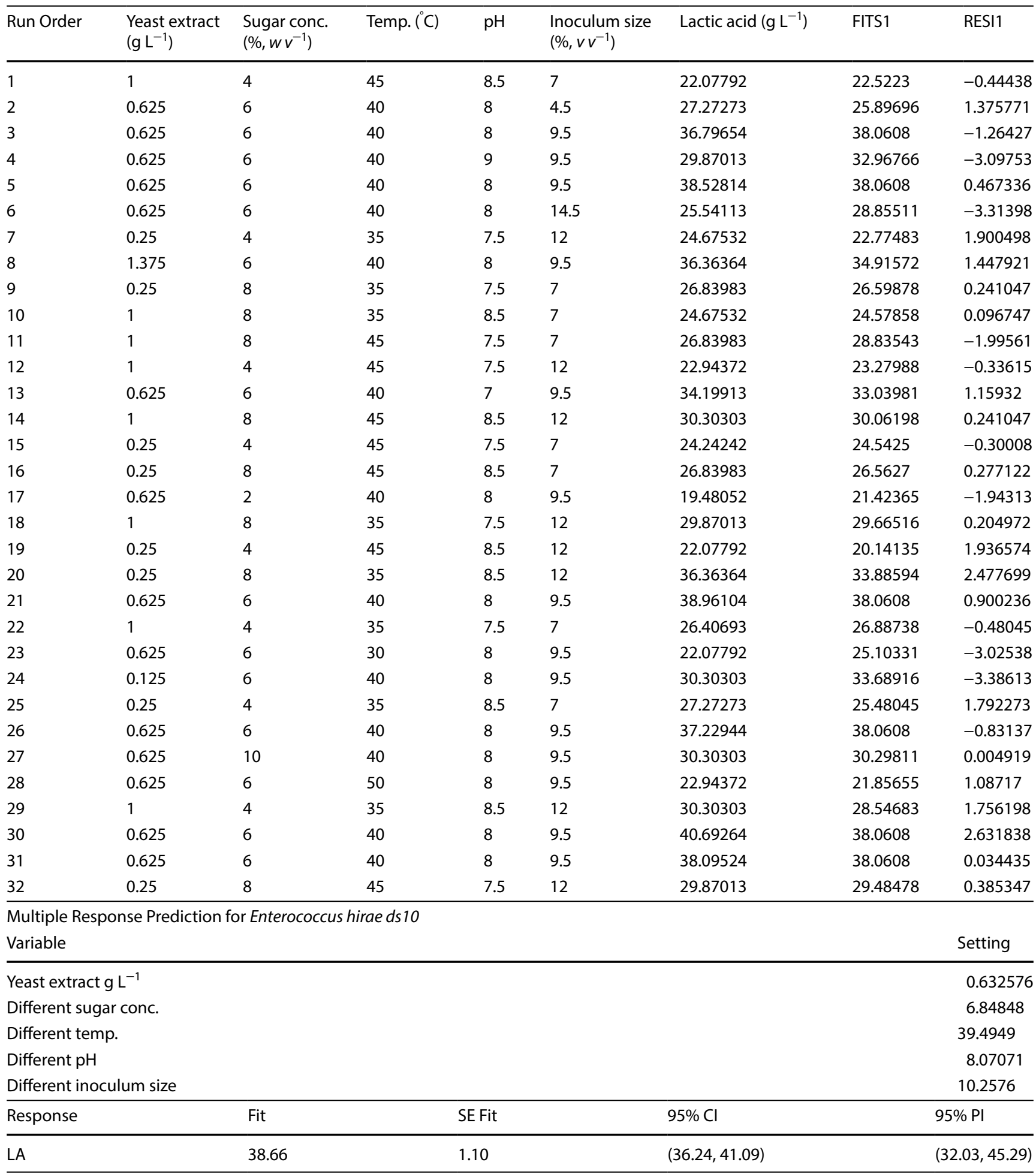

$50 \%$ of sugars (sucrose, fructose, glucose, and raffinose), nitrogen compounds, amino acids, organic acids, heavy metals, etc.[25].

Unfortunately, the direct utilization of molasses exhibited low LA production compared with the utilization of pure sugars (sucrose, glucose, and fructose). This might be attributed to the presence of metal ions/ inhibitory compounds that retard microbial growth. Abdel Aziz et al. [48] reported that beet-molasses contain high concentration of $\mathrm{Na}^{+}(986.8 \mathrm{mg} / 100 \mathrm{~g})$ 
and $\mathrm{K}^{+}(201 \mathrm{mg} / 100 \mathrm{~g})$. Besides this, it also contains high concentrations of $\mathrm{Fe}^{2+}(7.8 \mathrm{mg} / 100 \mathrm{~g})$, and $\mathrm{Zn}^{2+}$ $(12.6 \mathrm{mg} / 100 \mathrm{~g})$. Metal ions caused a critical problem during fermentation as it inhibited microbial growth, and inactivated the enzymatic activities associated with final product production [26]. Therefore, pretreatment steps for molasses are pending necessary to enhance the fermentation processes.

Amongst various chemical pretreatments methods, molasses treated by EDTA and $\mathrm{K}_{4}\left[\mathrm{Fe}(\mathrm{CN})_{6}\right.$ achieved higher LA concentrations compared with other methods. EDTA was chosen considering its low cost and it resulted in LA production at $11.39 \pm 2.07 \mathrm{~g} \mathrm{~L}^{-1}$ as compared to $2.01 \pm 0.02 \mathrm{~g} \mathrm{~L}^{-1}$ that obtained from untreated molasses. This might be attributed to the characteristics of these chemical agents as EDTA is a metal complexing agent and ferrocyanide ions might precipitate out the iron and zinc ions from the medium, and consequently decreased their toxic effect on the microbial strain and enhanced LA production [16, 25]. Tiwaki et al. [27] found that treatment of malt extract with EDTA has increased LA yield by Lactobacillus delbrueckii up to $1-2 \%$. It was found that the treatment of molasses with EDTA exhibited the highest LA production while treatment with sulphuric acid, tricalcium phosphate, and cation exchange resin showed an adverse effect on LA production by Lactobacillus delbrueckii NCIMB 8130 [25]. Also, the treatment of sweet potato starch hydrolysate with EDTA has enhanced citric acid production by Aspergillus niger IIB-A6 [28].

$L A B$ requires complex nutrients as they regarded as fastidious microorganisms that have limited ability to biosynthesize amino acid/vitamins [29]. Interestingly, molasses contains nitrogen and vitamin substrates in its composition that might save the nitrogen source cost [30]. For fermentation cost reduction, LA-fermentation of pre-treated molasses with/without external nutrient supplementation was investigated. We notice that there is no big difference between fermentation conducted with or without MRS fortified with yeast extract only. LA fermentation by $E$. faecalis was significantly affected by yeast extract concentration [26].

As yeast extract is one of the expensive component [38\% of total medium-cost [31, 32]. Therefore, alternative and cheaper nitrogen sources are particularly recommended. For that, we studied the effects of substitution yeast extract with other lower-cost nitrogen sources. However, the highest LA production was obtained using yeast extract. But the substitution of yeast extract with ammonium chloride has achieved good results. Ammonium sulfate [33] and malt combing nuts [34] were reported as good alternatives to yeast extract for LA production. Ammonium chloride was used as a nitrogen source and yeast extract as a growth promoter for LA fermentation from sugarcane and cassava bagasse by Lactobacillus delbrueckii [35].

Further investigation was conducted to minimize medium cost. We used ammonium chloride as nitrogen source with yeast extract, dried yeast cells or dried fish wastes as vitamin source at different concentrations. Interestingly, the best result was obtained with the lowest concentration of yeast extract at $0.5 \mathrm{~g} \mathrm{~L}^{-1}$. Therefore, utilization of molasses (substrate) supplemented with $5 \mathrm{~g}$ $\mathrm{L}^{-1}$ ammonium chloride (nitrogen source) and $0.5 \mathrm{~g} \mathrm{~L}^{-1}$ yeast extract (vitamin source) would achieve better competitive cost for industrial production of LA by Enterococcus hirae ds 10. It was also reported that increased nitrogen concentration adversely affects fermentation kinetics [36]. Our results indicated that supplementation of dried yeast cells and fish wastes did not improve LA production by strain ds 10 . Besides this, the mixed ammonium chloride with fish wastes exhibited very low concentration of lactic acid $\left(0.29-0.86 \mathrm{~g} \mathrm{~L}^{-1}\right)$, lower than that obtained on molasses with only ammonium chloride $\left(4.04 \mathrm{~g} \mathrm{~L}^{-1}\right)$. This might be attributed to some inhibitory components in fish waste materials. Similarly, Shi et al. [37] reported that the efficiency of LA production from glucose was greatly reduced when the unhydrolyzed fish manure wastes (Nile tilapia and channel catfish) were used instead of yeast extract using Lactobacillus pentosus. On the other hand, Gao et al. [38] have reported that acid hydrolyzed fish wastes showed high efficiency for LA production and could be used as a substitute for YE.

To find the optimum conditions for LA production by strain ds 10 , we studied factors affecting LA production using a one-factor-at-a-time (OFAT) approach and a statistical approach $[4,29]$. The highest LA concentration was obtained with an initial sugar concentration of $20 \mathrm{~g} \mathrm{~L}^{-1}$. But as expected, lower growth rate, LA concentration, and high residual sugars were obtained at higher sugar concentrations indicating substrate inhibition. It was reported that LA production by Lactobacillus delbrueckii NCIMB 8130 was increased with an increase of initial beet molasses sugar concentration up to $100 \mathrm{~g} \mathrm{~L}^{-1}$ [25].

$\mathrm{pH}$ is one of the factors influencing the metabolic and enzymatic activities of the microorganisms [29]. During the LA fermentation process, $\mathrm{pH}$ was decreased that affected the fermentation process. Therefore, we speculated that the addition of neutralizing agents would partially overcome such inhibition. Unexpected, addition of neutralizing agent (calcium carbonate/sugar conc., 2:1) exhibited an adverse effect on the LA fermentation process. It was found that a high concentration of $\mathrm{CaCO}_{3}$ than $7 \%$, $(w / v)$ exhibited a negative effect on LA production [25]. On contrast, $\mathrm{CaCO}_{3}(10 \%, w / v)$ in the production medium exhibited a good effect on LA production by Lactobacillus $L M I 8$ sp. [36]. Therefore, we might attribute such inhibition 
depending on special reactions with the used substrate or due to strain specificity. Overall, our study would result in LA production with no environmental wastes (i.e. gypsum) due to no use of $\mathrm{CaCO}_{3}$ in fermentation processes.

To find the influence of the initial $\mathrm{pH}$ of the medium, the $\mathrm{pH}$ of the fermentation medium was adjusted to varying $\mathrm{pH}$. The maximum LA production by Enterococcus hirae ds10 $\left(11.26 \pm 0.35 \mathrm{~g} \mathrm{~L}^{-1}\right)$ was observed at $\mathrm{pH}$ 8.0. However, at higher and lower $\mathrm{pH}$ levels, a decrease in all parameters were obtained. It was reported that the optimal $\mathrm{pH}$ for $L A$ production by most $L A B$ varies between $5.0-7.0$, being dependent on the microbial species [40]. pH 6.5 was the optimal for LA production by Enterococcus faecium No. 78 [41].

Temperature is one of the critical factors affecting growth rate and metabolite production [42, 43]. Our results showed that LA production was markedly influenced by the initial temperature whereas optimal fermentation temperature for Enterococcus hirae ds 10 was $40^{\circ} \mathrm{C}$. At lower or higher temperature, the strain showed lower biomass and LA production, but interestingly, this strain can tolerate higher temperature until $50^{\circ} \mathrm{C}$. LA production by Enterococcus faecium S.156 was almost steady from $32-40{ }^{\circ} \mathrm{C}$ [39]. Tan et al. (2017) reported that optimal LA production by Enterococcus faecium QU 50 was obtained at $50^{\circ} \mathrm{C}$.

The effect of inoculum size on LA production was also studied. The maximum LA production by Enterococcus hirae ds 10 of $25.40 \pm 0.42 \mathrm{~g} \mathrm{~L}^{-1}(24 \mathrm{~h})$ was obtained using a $10 \%(v / v)$ inoculum size. According to [4], the inoculum size is usually $5-10 \%(\mathrm{v} / \mathrm{V})$ of the working volume. The inoculum size $10 \%(\mathrm{v} / \mathrm{v})$ was used for the production of LA from Bacillus sp. [44], and Lactobacillus amylophilus GV6 [45].

Response surface Minitab 18 software was used to optimize the composition of the medium. This method is very economical and efficient as it studies the relationships between various independent variables [46]. According to the regression model, the maximum LA concentration $\left(40.69 \mathrm{~g} \mathrm{~L}^{-1}\right)$ was reached at $0.625 \mathrm{~g} \mathrm{~L}^{-1}$ yeast extract, $60 \mathrm{~g}$ $\mathrm{L}^{-1}$ sugar concentration, $40^{\circ} \mathrm{C}, \mathrm{pH} 8.0$ and $9.5 \%$ inoculum size. The optimal temperature, and $\mathrm{pH}$ defined by the model were as the same as earlier experiments, however, the inoculum size and yeast extract were slightly differ with $9.5 \%$ and $0.625 \mathrm{~g} \mathrm{~L}^{-1}$ from $10 \%$ and $0.5 \mathrm{gL}^{-1}$, respectively. With this parameter, the carbon source was increased from $40 \mathrm{~g} \mathrm{~L}^{-1}$ to $60 \mathrm{~g} \mathrm{~L}^{-1}$ and exhibited maximum LA concentration at $40.69 \mathrm{~g} \mathrm{~L}^{-1}$ that is almost double the amount compared by maximum LA produced [25.4 $\left.\pm 0.42 \mathrm{~g} \mathrm{~L}^{-1}(24 \mathrm{~h})\right]$ by classical OFAT. Altaf et al. [47] used response optimization with MINITAB-13 and found that the possible LA output to be $4.5 \mathrm{~g}$ from the highest output of LA production observed was $3.8 \mathrm{~g} / 6.0 \mathrm{~g}$ starch present in $10 \mathrm{~g}$ of wheat bran. As have been noted from both optimization methods, high residual sugar concentration has limited the fermentation. This might be attributed to the high LA concentrations that lead to decreased $\mathrm{pH}$ value affecting the enzymatic activities for further sugar utilization. The increased free LA might also inhibit bacterial growth and retard fermentation. Although utilization of $\mathrm{CaCO}_{3}$ as a neutralizing agent did not overcome this problem, therefore, further investigations utilizing various neutralizing agents would be necessary for studies.

\section{Conclusion}

Our results conclude the possibility of using molasses as an economical source for LA production after pretreatment using EDTA. Ammonium chloride is a good alternative nitrogen source that replaced the traditional costly yeast extract in the optimized medium by using yeast extract as a vitamin source at very low concentration $(0.05 \%, w / v)$. Homolactic acid fermentation by Enterococcus hirae ds 10 was optimized by a statistical method that increased about two-folds than by traditional method on low-cost medium contained beet molasses, ammonium chloride, and yeast extract. Further enhancement was obtained using a statistical method that evaluated the most efficient factors affected LA production achieving $40.69 \mathrm{~g} \mathrm{~L}^{-1}$ in low-cost production medium.

Acknowledgements The authors are thankful to Dr. Mahmoud Gaber and members of Fermentation Biotechnology and Applied Microbiology Centre, Al-Azhar University for their great support and contributions through this work.

Data Availability The data used to support the findings of this study are available from the corresponding author upon request.

\section{Compliance with ethical standards}

Conflict of interest Authors declare that there are no conflicts of interest.

\section{References}

1. Abdel-Rahman MA, Tashiro Y, Sonomoto K (2013) Recent advances in lactic acid production by microbial fermentation processes. Biotechnol Adv 31:877-902

2. Dumbrepatil A, Adsul M, Chaudhari S, Khire J, Gokhale D (2008) Utilization of molasses sugar for lactic acid production by Lactobacillus delbrueckii subsp. delbrueckii mutant Uc-3 in batch fermentation. Appl Environ Microbiol 74:333-335

3. Abdel-Rahman MA, Sonomoto K (2016) Opportunities to overcome the current limitations and challenges for efficient microbial production of optically pure lactic acid. J Biotechnol 236:176-192 
4. Ghaffar T, Irshad M, Anwar Z, Aqil T, Zulifqar Z, Tariq A, Kamran M, Ehsan N, Mehmood S (2014) Recent trends in lactic acid biotechnology: a brief review on production to purification. J Radiat Res Appl Sci 7:222-229

5. Rasmey AHM, Hawary H, Wahid OAA, Abo-Seidah AA (2018) Enhancing bioethanol production from sugarcane molasses by Saccharomyces cerevisiae Y17. Egypt J Bot 58:547-561

6. Keshk SM, Razek TM, Sameshima K (2006) Bacterial cellulose production from beet molasses. Afr J Biotech 5:1519-1523

7. Xu K, Xu P (2014) Efficient production of L-lactic acid using co-feeding strategy based on cane molasses/glucose carbon sources. Biores Technol 153:23-29

8. John RP, Nampoothiri KM, Pandey A (2007) Fermentative production of lactic acid from biomass: an overview on process developments and future perspectives. Appl Microbiol Biotechnol 74:524-534

9. De la Torre I, Ladero M, Santos VE (2018) Production of D-lactic acid by Lactobacillus delbrueckii ssp. delbrueckii from orange peel waste: techno-economical assessment of nitrogen sources. Appl Microbiol Biotechnol 102:10511-10521

10. Abdel-Rahman MA, Tashiro $Y$, Zendo T, Sonomoto K (2013) Improved lactic acid productivity by an open repeated batch fermentation system using Enterococcus mundtii QU 25. RSC Adv 3:8437-8445

11. Singh V, Haque $S$, Niwas $R$, Srivastava A, Pasupuleti M, Tripathi CKM (2017) Strategies for fermentation medium optimization: an in-depth review. Front Microbiol 7:2087

12. Panda BP, Ali M, Javed S (2007) Fermentation process optimization. Res J Microbiol 2:201-208

13. Kennedy M, Krouse $D$ (1999) Strategies for improving fermentation medium performance: a review. J Ind Microbiol Biotechnol 23:456-475

14. Cazetta ML, Celligoi MAPC, Buzato JB, Scarmino IS (2007) Fermentation of molasses by Zymomonas mobilis: Effects of temperature and sugar concentration on ethanol production. Biores Technol 98:2824-2828

15. De Man JC, Rogosa D, Sharpe ME (1960) A medium for the cultivation of lactobacilli. J Appl Microbiol 23:130-135

16. Claus D (1992) A standardized Gram staining procedure. World J Microbiol Biotechnol 8:451-452

17. Benson (2001) Microbiological applications (laboratory manual in general microbiology), 8th Ed. The McGraw-Hill, New York, pp 381

18. Roukas T (1998) Pretreatment of beet molasses to increase pulIulan production. Process Biochem 33:805-810

19. Küçükaşik F, Kazak H, Güney D, Finore I, Poli A, Yenigün O, Nicolaus B, Öner ET (2011) Molasses as fermentation substrate for levan production by Halomonas sp. Appl Microbiol Biotechnol 89:1729-1740

20. Taylor KA (1996) A simple colorimetric assay for muramic acid and lactic acid. Appl Biochem Biotechnol 56:49-58

21. Dubois M, Gilles KA, Hamilton JK, Rebers PT, Smith F (1956) Colorimetric method for determination of sugars and related substances. Anal Chem 28:350-356

22. Subramanian MR, Talluri S, Christopher LP (2015) Production of lactic acid using a new homofermentative Enterococcus faecalis isolate. Microb Biotechnol 8:221-229

23. Narayanan N, Roychoudhury PK, Srivastava A (2004) L(+) lactic acid fermentation and its product polymerization. Electron $\mathrm{J}$ Biotechnol 7:167-178

24. He X, Chen K, Li Y, Wang Z, Zhang H, Qian J, Ouyang P (2015) Enhanced L-lysine production from pretreated beet molasses by engineered Escherichia coli in fed-batch fermentation. Bioprocess Biosyst Eng 38:1615-1622

25. Kotzamanidis $\mathrm{CH}$, Roukas $\mathrm{T}$, Skaracis G (2002) Optimization of lactic acid production from beet molasses by Lactobacillus delbrueckii NCIMB 8130. World J Microbiol Biotechnol 18:441-448

26. Wee YJ, Kim JN, Yun JS, Ryu HW (2004) Utilization of sugar molasses for economical $\mathrm{L}(+)$-lactic acid production by batch fermentation of Enterococcus faecalis. Enzyme Microbial Technol 35:568-573

27. Tiwake KP, Mishra N, Pandey A (1980) Influence of EDTA and its metal complexes on lactic acid fermentation. Zentralblatt für Bakteriologie, Parasitenkunde, Infektionskrankheiten und Hygiene. Zweite Naturwissenschaftliche Abteilung: Mikrobiologie der Landwirtschaft, der Technologie und des Umweltschutzes. 135, 223-225.

28. Anwar S, Ali S, Sardar AA (2009) Citric acid fermentation of hydrolysed raw starch by Aspergillus niger IIB-A6 in stationary culture. Sindh Univ Res J-SURJ (Sci Ser) 41:1-8

29. Mussatto SI, Fernandes M, Mancilha IM, Roberto IC (2008) Effects of medium supplementation and $\mathrm{pH}$ control on lactic acid production from brewer's spent grain. Biochem Eng J 40:437-444

30. Monteagudo JM, Rodríguez L, Rincón J, Fuertes J (1997) Kinetics of lactic acid fermentation by Lactobacillus delbrueckii grown on beet molasses. J Chem Technol Biotechnol Int Res Process Environ Clean Technol 68:271-276

31. Altaf MD, Venkateshwar M, Srijana M, Reddy G (2007) An economic approach for L-(+) lactic acid fermentation by Lactobacillus amylophilus GV6 using inexpensive carbon and nitrogen sources. J Appl Microbiol 103:372-380

32. Moldes AB, Alonso JL, Parajo JC (2001) Strategies to improve the bioconversion of processed wood into lactic acid by simultaneous saccharification and fermentation. J Chem Technol Biotechnol 76:279-284

33. Nancib A, Nancib N, Meziane-Cherif D, Boubendir A, Fick M, Boudrant J (2005) Joint effect of nitrogen sources and B vitamin supplementation of date juice on lactic acid production by Lactobacillus casei subsp. rhamnosus. Biores Technol 96:63-67

34. Pauli T, Fitzpatrick JJ (2002) Malt combing nuts as a nutrient supplement to whey permeate for producing lactic by fermentation with Lactobacillus casei. Process Biochem 38:1-6

35. John RP, Nampoothiri KM, Pandey A (2006) Solid-state fermentation for L-lactic acid production from agro wastes using Lactobacillus delbrueckii. Process Biochem 41:759-763

36. de Lima CB, Coelho LF, Blanco KC, Contiero J (2009) Response surface optimization of $\mathrm{D}(-)$-lactic acid production by Lactobacillus SMI8 using corn steep liquor and yeast autolysate as an alternative nitrogen source. Afr J Biotech 8:5842-5846

37. Shi S, Li J, Blersch DM (2018) Utilization of solid catfish manure waste as carbon and nutrient source for lactic acid production. Appl Microbiol Biotechnol 102(11):4765-4772

38. Gao MT, Hirata M, Toorisaka E, Hano T (2006) Acid-hydrolysis of fish wastes for lactic acid fermentation. Bioresour Technol 97:2414-2420

39. Sun W, Liu J, Xu H, Li W, Zhang J (2015) L-Lactic acid fermentation by Enterococcus faecium: a new isolate from bovine rumen. Biotech Lett 37:1379-1383

40. Hofvendahl K, Hahn-Hägerdal B (2000) Factors affecting the fermentative lactic acid production from renewable resources 1 . Enzyme Microbial Technol 26:87-107

41. Shibata K, Flores DM, Kobayashi G, Sonomoto K (2007) Direct L-lactic acid fermentation with sago starch by a novel amylolytic lactic acid bacterium, Enterococcus faecium. Enzyme Microbial Technol 41:149-155

42. Hujanen M, Linko YY (1996) Effect of temperature and various nitrogen sources on $\mathrm{L}(+)$-lactic acid production by Lactobacillus casei. Appl Microbiol Biotechnol 45:307-313

43. Qin H, Gong SS, Ge XY, Zhang WG (2012) The effect of temperature on L-lactic acid production and metabolite distribution of Lactobacillus casei. Prep Biochem Biotechnol 42:564-573 
44. Wang L, Zhao B, Liu B, Yu B, Ma C, Su F, s., Hua, D. \& Xu, P., (2010) Efficient production of L-lactic acid from corncob molasses, a waste by-product in xylitol production, by a newly isolated xylose utilizing Bacillus sp. strain. Biores Technol 101:7908-7915

45. Vishnu C, Seenayya G, Reddy G (2002) Direct fermentation of various pure and crude starchy substrates to $L(+)$ lactic acid using Lactobacillus amylophilus GV6. World J Microbiol Biotechnol 18:429-433

46. Gao X, Qiao SY, Lu WQ (2009) Determination of an economical medium for growth of Lactobacillus fermentum using response surface methodology. Lett Appl Microbiol 49:556-561

47. Altaf MD, Naveena BJ, Venkateshwar M, Kumar EV, Reddy G (2006) Single step fermentation of starch to $L(+)$ lactic acid by
Lactobacillus amylophilus GV6 in SSF using inexpensive nitrogen sources to replace peptone and yeast extract-optimization by RSM. Process Biochem 41:465-472

48. Abdel-Aziz SM, Hamed HA, Mouafi FE, Gad AS (2012) Acidic $\mathrm{pH}$-shock induces the production of an exopolysaccharide by the fungus Mucor rouxii: utilization of beet-molasses. NY Sci J 5(2):52-61

Publisher's Note Springer Nature remains neutral with regard to jurisdictional claims in published maps and institutional affiliations. 